\title{
Crosslinguistic Influence of L1 (Arabic) in Acquiring Linguistic Items of L2 (English): An Empirical Study in the Context of Arab Learners of English as Undergraduate Learners
}

\author{
Anwar Mourssi \\ Faculty of Arts, Creative Industries and Education, University of the West of England, Bristol, UK
}

\begin{abstract}
This study investigates one of the most common issues namely the crosslinguistic influence of the $\mathbf{L 1}$ in learning $\mathbf{L} 2$ grammar, specifically the acquisition of the simple past tense. The researcher believes that the simple past tense forms produced by learners sometimes appear to have originated in $\mathrm{L} 2$ and sometimes in L1. An empirical study was conducted on 74 Arab Learners of English (ALEs) which lasted four months. A detailed analysis was made of the acquisition of the simple past tense forms in 222 written texts produced by ALEs. Written texts were collected chronologically from each subject at three stages in the experiment. Quantitative analysis shows the crosslinguistic influence of $\mathrm{L1}$ (Arabic) in acquiring the linguistic items of $\mathrm{L2}$ (English) in general and in acquiring the simple past in particular.
\end{abstract}

Index Terms - interlanguage, SLA, crosslinguistic influence, overgeneralization, simple past

\section{INTRODUCTION}

In general, Odlin (1989, p. 6), and Larsen-Freeman and Long (1991, p. 5) mentioned that "the study of transfer, or crosslinguistic influence, is peculiar among language acquisition and the phenomenon of language use". In particular, Jarvis and Pavlenko (2008, p. 4) argued that crosslinguistic influence refers to the influence of one language on another in an individual mind. They illuminated several areas of meaning and crosslinguistic influence which had not been carefully looked at before. They presented interesting findings and an analysis of the relationship between language transfer and SLA. Based on Odlin's (1989) claimed, and Jarvis and Pavlenko's (2008) findings, the study will investigate the role of L1 in the acquisition of the simple past in the context of ALEs. This will be presented in section two, and more specifically in section four. Briefly, there are four elements used to support the role of transfer in interlanguage, which are: natural languages, universal grammar, L1 transfer, and Markedness.

This paper is divided into six main sections: section one is the introduction, the literature review is presented in section two, section three describes the methods used in the current study, the analysis and the discussion are presented in section four, the conclusion is discussed in section five, and finally, the references are presented in section six. The following section presents the literature review.

\section{LITERATURE REVIEW}

One of the assumptions of the study is that the concept of Interlanguage has had an important effect on the SLA field. I will first outline the definition of Interlanguage since interlanguage is studied by many researchers who identify this system differently. Then I will explore how Interlanguage might vary between the L1and the L2, referring to the role of transfer in interlanguage.

\section{A. The Interlanguage Model}

Following Selinker's (1969) ground-breaking paper, most SLA researchers nowadays recognize that second/foreign language learners go through a series of steps when learning a language. This is called Interlanguage. A study of interlanguage may shed light on how Arab learners of English improve their internal grammar. First of all we have to consider that it is difficult to examine interlanguage competences directly. Instead, indirectly information about the nature of interlanguage competence can only be derived; this might happen through an examination of interlanguage performance data which come in the form of writing sentences, grammatical forms and spontaneous speech, as Lakshmanan \& Selinker (2001,p. 393) pointed out.

The interlanguage hypothesis is defined as the hypothesis that the language learners have a grammatical system that is different from both the first language and the target language but is nevertheless a natural language. That is, interlanguage is believed to be constrained by the same principles as all languages. Ellis (1997) defined interlanguage as a term referring to the variable progression through which a system of abstract linguistic rules is developed. RichardAmato (2003, p. 37) commented that "this process reflects the systematic development of the syntax, semantics, and 
pragmatics of the second language and is very similar to the process followed by first language learners. Throughout, hypothesis testing occurs usually at the subconscious level and predictable errors are made along the way, regardless of what first language the students speak". Gass and Selinker (2008) commented that L1 transfer has elements in universal language acquisition in general. According to Ellis (1997, p. 33), learners' knowledge about the grammar rules changes and develops. Such knowledge adds and deletes new rules to their mental lexicon over time. Generally, when learners start to learn the language, they begin to learn the simple rules first then they gradually move to the more complex ones. For example, they start first to learn the use of a verb like "write" in the present simple then they move to learn the other forms such as wrote, writing,....and so on.

According to Crystal (2008, p. 239), "Interlanguage reflects the learner's evolving system of rules, resulting from a variety of processes, including the influence of the first language ('transfer'), contrastive interference from the target language, and the overgeneralization of newly encountered rules."

Some studies (Pienemann, 1984, 1998; Williams and Evans, 1998; Spada and Lightbown, 1999) based on developmental sequences indicate that instruction may have facilitative effects on L2 acquisition but its effectiveness may be constrained by the learners' readiness for development, which may be further mediated by L1 transfer or other L1-based factors.

According to Cook (2001, p. 14), elements in the first language help learners with the second language if both share common elements but hinder them when they differ. On the other hand, it still cannot be considered that the first language is the main culprit or the sole cause for all the errors in learning a second language. Some linguists have classified errors into: interlingual errors related to L1 and intralingual errors related to L2 (Richards 1974, p. 173), and in-between errors which may originate in L1 and/or in L2 as well, (Mourssi, 2012a, and 2012c).

The main aim of the current study is investigate the crosslinguistic influence of the L1 in learning L2 grammar, specifically the acquisition of the simple past tense. The researcher believes that the simple past tense forms produced by learners sometimes appear to have originated in L2 and sometimes in L1 as well.

Lakshmanan and Selinker (2001, p. 394) are convinced that "important advances were achieved in relation to L2 developmental sequences based on spontaneous speech samples, gathered longitudinally in the 1970s. However, the use of longitudinal data appears to have declined in popularity in the 1980s". They added, the situation changed again in the 1990s when SLA researchers began to use longitudinal spontaneous data to get true facts about the language learners' mental representations of the L2. It is worth mentioning that the current study lasted for only four months and can thus give only a partial view of the interlanguage stages ALEs go through in the acquisition of the simple past tense, by which, crosslinguistic influence of L1 in acquiring L2 grammar can be observed.

In interlanguage studies, a method comparing two languages that focuses more heavily on L2 concerns is likely to have a disastrous effect on investigation. Hence, as Adjemian (1976) has stressed, the importance of investigating interlanguage competence should be done without bias to either the native language or the target language systems. In the current study, the author tries to identify the non-target-like simple past forms produces by ALEs whether they originated in L2 or in L1.

As Lakshmanan and Selinker (2001, p. 397) stressed, "an effective comparison of the development of individual interlanguage grammar may be difficult to accomplish". One reason is that the results cannot be generalized to all L2 learners. Another reason is that the part that is visible to us (their spoken or written work) is often a locus of performance error. And, although learners have already acquired the target-like form, there is still a strong tendency that they will slip back to the former but non-target-like ways. In the following, I will present variation in interlanguage.

\section{Variation}

Learners have to cope with considerable variability in the target language. Two words might be used alternatively in order to show one particular function of a language. The following example indicates the way that the learner might use to exchange between "not" and "no".

The sun not shine

No reference.

Gass and Selinker (2008, p. 259-260) stated that in this case, the two negating words are used alternatively without a clear difference in meaning between them. As a result, non-systematic disparity was adopted to refer to these two forms. When the learners become more proficient in the language which they are exposed to, they start to predict their suitable ways of non-systematic usage.

According to Fasold and Preston (2007) the fundamental element which underlies the appearance of target-like usage is variation. For example, the learner might say under one condition "I don't" as a target-like variant and "Me no" as a non-target-like variant in another condition. Linguists have interpreted this observable fact according to two dimensions. One group said that variability is related to what they call "performance errors" as they followed a Chomskyan perspective to SLA. They believed that it did not have anything to do with systematic questions. Other linguists related the variability to sociolinguistic or psycholinguistic factors. They said that variability is an innate characteristic of the learner's language. In this case the learner relies on the relation between the social and contextual variables in the selection process of using one linguistic variant rather than the other one.

Ellis (1984) monitored an 11- year old Portuguese learner who learned English as a second language. Ellis focused on the learner's use of the forms "no and don't" and found out that the learner tended to use "no" more frequently than 
"don't" at the beginning of his study. When he became more familiar with English, he reduced the use of "no" and the use of "don't" became more frequent. Moreover, Gass and Selinker (2008) mentioned that there are two different types of variations which are free variation and systematic variation.

According to Tarone, Bigelow and Hansen (2009), when learners spend more time in planning, their use of the target language will extend and improve. Learners will be able to perform better in a writing task where they have enough time to plan than in a speaking context where they do not have adequate time to do so. In one of the recent studies which was carried by Mourssi (2012d), the author indicated that when second/foreign language learners have enough time to reprocess the input in speaking context, they perform better.

Additionally, affective factors have a clear effect on systematic variation. For example, learners produce more targetlike forms when they feel comfortable. Such production is decreased when they encounter a stressful situation like having a formal exam. Therefore, social factors play an important role in systematic variation. In the following, I will shed some light on the role of transfer in interlanguage.

\section{B. The Role of Transfer in Interlanguage}

Transfer is one of the most important elements which affect interlanguage forms. Investigating it might guide us to a better understanding of the source/origin and the development of interlanguage. Researchers were doubtful about the issue of transfer, but some of them have said that it is related to language acquisition and should be discussed. Lado (1957) believed that people rely on their first language when they learn the target language, which has been recently confirmed in an empirical study carried out by Mourssi (2012a). On the other hand, other researchers Dulay and Burt (1974, p. 24) said that transfer has nothing to do with interlanguage.

As it is mentioned in the introduction, Odlin (1989, p. 6), and Larsen-Freeman and Long (1991, p. 5) mentioned that "the study of transfer, or crosslinguistic influence, is peculiar among language acquisition and the phenomenon of language use". In particular, Jarvis and Pavlenko (2008, p. 4) argue that crosslinguistic influence refers to the influence of one language on another in an individual mind. They illuminated several areas of meaning and crosslinguistic influence which had not been carefully looked at before. They presented interesting findings and an analysis of the relationship between language transfer and SLA. Based on Odlin's (1989) claims, and Jarvis and Pavlenko's (2008) findings, the study will investigate the role of L1 in the acquisition of the simple past in the context of ALEs.

Another model which may shed light on the interlanguage data to do with simple past tense forms is the Words and Rules model. Mourssi (2013) discussed and evaluated the Words and Rules model and its implementations in Herschensohn's study in detail. In what follow, The context of Arab Learners of English and acquiring grammar, which includes the importance of grammar in learning L1 and its impact on learning L2 in section 2.3.1 and the seven categories werev expected to be found in the ALEs' context in acquiring simple past in English (Mourssi, 2012a, and 2012c) in section 2.3.2.

\section{The Context of Arab Learners of English and Acquiring Grammar}

Mourssi (2012a, 2012d) indicated that Arabic does not follow English grammatical structure. Mansouri (2005, p. 118) refers to the difficulties in Arabic acquisition and its specific typology. This perception that verbal morphology may be complex gives the ALEs an impression about English grammar and motivates them to learn English grammar in a thoroughgoing way. This section consists of two sub-sections. First in 2.3.1, I will present the importance of grammar in learning the L1 and its impact on learning the L2. In 2.3.2, I will present the acquisition of the simple past in the context of ALEs.

The Importance of Grammar in Learning L1 and its Impact on Learning L2

Mourssi (2013a, 2013b) mentioned that prescriptive Arabic grammarians think that grammar is the only element which shows how language is used. They also view the traditional grammar of any language as a set of rules, and the major concept in learning language is to learn its grammar first. According to them, the most common and appropriate learning strategy of learning is memorization, which is reflected in the way they learn L2. They think that memorization helps learners to achieve the tasks required in learning the target language better than any other strategy. This affects the methods of teaching followed by teachers of English for Arab learners who try to achieve the objectives of the target task in a proper and a suitable way which matches learners' attitudes. Similarly, it affects the way Arab learners of English acquire a second language in general and second language grammar in particular. This view is also reflected in the SLA research done based on samples taken from Arabic speakers of English.

Grammar can be viewed in different ways in learning English (as an L1 or L2). Hymes (1972) stated English speakers need to know the rules of grammar with the rules of language use in order to communicate in a language. Dickins and Woods (1988, p. 630) believed that the role of grammar is to convey and interpret meanings. While Fuller and Gundel (1987, p. 70) suggested that grammatical rules (patterns that are studied by syntacticians and morphologists) were basically designed to help people get their meaning across clearly and accurately.

Furthermore, it is claimed that grammar is essential for appropriate communication. Lock (1996, p. 267) posited that language is a resource for communication and claimed that grammar lies at the heart of communication and is not an optional add-on to communication. Similarly, Leech and Svartvik (1982:4) viewed grammar as the focal part of language which relates to phonology and to semantics as well. Harmer (1991, p. 23) believed that knowledge of 
grammar is essential for competent users of a language. Larsen-Freeman and Long (1991) asserted that grammar is one of three interconnected dimensions of language which include: grammar, semantics and pragmatics.

Similar to the perspectives offered by Arab language grammarians, Klein (1986) postulated that in order to learn a second/foreign language, learners should have the ability to analyse the linguistic input in the target language. More recently, Gao (2001, p. 326) described grammar as a catalyst for second language accuracy and fluency.

Ismail (2010, p. 143) demonstrated that "Arab learners of English had positive views about the use of the CCCC grammar model, which is presented in four stages: Confrontation, Clarification, Conformation, and Consolidation". The author also highlighted certain students' beliefs about the importance and the positive influence of explicit grammar teaching for learning the conventions of sentences and utterances.

With respect to what has been mentioned in the previous literature related to explicit and implicit grammar learning/teaching and the conclusion that explicit grammar learning/teaching is more effective than implicit grammar learning/teaching, it is hypothesized that it might be better for teachers of English for Arab learners of English to use explicit grammar learning/teaching when the grammatical item is difficult to be learnt based on the level of the learners, and to use implicit grammar teaching when the grammatical item is easy to be perceived, (Mourssi, 2013). This view is supported by Cross (1991) and Scarcella and Oxford (1992). In other words, an explicit grammar teaching method is to be followed with weak language learners, while an implicit grammar teaching is to be followed with higher level language learners. In the following, the stages found in the acquisition of the simple past in the context of ALEs will be presented.

The following seven categories were found in the ALEs' context in acquiring simple past in English (Mourssi, 2012a, 2012c):

1- Use the root or simple present form (E.g. go, come, stay, calls, help)

2- Use spoken target-like form but in a written non-target-like form (E.g. brook, wint, hapeend, trayed, colled)

3- Overgeneralizing the -ed to irregular verbs (E.g. catched, gived, taked, comed, leaved)

4- Use verb to "Be" + simple past, past participle or gerund etc. (E.g. were wanted, was came, was started, was broke, were became, is happening)

5- Misselecttion of the target-like verb from (E.g. they was, he were, she were, the woman were, the driver were)

6- Use blended forms

A- Use have, has + simple past or past participle (E.g. has went, have helped, has arrived)

B- Use infinitive + past simple or past participle (E.g. to went, to called, to moved, to seen,)

7- Overgeneralizing a sub-rule of irregular simple past on other irregular simple past or regular simple past (E.g. brang, stold, foul), (Mourssi, 2012a, 2012c).

In the following section, methods used in the current study will be presented.

\section{METHODS}

This section discusses the subjects of the study, the research question and the methods used in the analysis of the written texts.

\section{A. The Subjects of the Study}

Based on the results of a placement test, two classes were selected from a total of 12 enrolled in grade 12. The target location was in one of the Omani government secondary schools (High School). Each group consisted of 37 Arab Learners of English (ALEs), with ages ranging between 16 and 18, pre-intermediate to intermediate level in English. The subjects were all Arabic speakers and had been learning English as a foreign language for eight years attending four to five sessions per week on average. One aim of the current study is to investigate the crosslinguistic influence of L1 (Arabic) in acquiring linguistic items of L2 (English)

\section{B. The Research Question}

The current study seeks to answer the following question:

What is the evidence of L1 (Arabic) influence in the acquisition of L2 (English) linguistic items? This is to provide empirical evidence in relation to the acquisition of the simple past tense forms to test hypotheses emerging from language transfer and thus contribute to the advancement of theory on Second Language Acquisition.

\section{Methods Assigned to the Research Question}

For the research question presented above, quantitative analyses were followed for all the simple past tense forms produced by the samples in 222 written texts which had been collected chronologically. The author thinks that in order to explore interlanguage phenomena and the influence of L1 in acquiring linguistic items of L2, three writing texts were collected from each sample in both groups, the first writing text (B) was collected after the first two weeks; the second writing (M) after the first two months while the third writing (F) was collected at the end of the experiment. Writing is one way to get evidence of the state of a student's internalised grammar system. Discussion will be presented in the following section. 


\section{DISCUSSION}

The analysis of the simple past forms produced by the ALEs in the three chronological pieces of writing, appears to indicate that Arabic Language has influence in the acquisition of English simple past, e.g. how can are went, was came, was gave, to went, to visited, and has went. It was interesting to find the contrastive interference from the target language in the current study, finding in the current study, namely overgeneralization of newly encountered rules, where learners overgeneralize L2 structure on forming another linguistic item.

By comparing the stages mentioned above related to the acquisition of the simple past in the context of ALEs, in section 2.3.2. with other researches' findings, it is noticed the similarities between the coding of Interlanguage stages of these studies and my own coding of Interlanguage stages in the current study, and it is noticed the differences occur might be due to the nature of Arabic language grammar and its influence in SLA.

It might be argued that two proposed explanations for the simple past forms which represent the influence of Arabic Language (stage 4 and stage 6.B) in acquiring the simple past in English are as follows: firstly, it may be L1 transfer where learners try to apply some rules from L1 on their performance in L2; secondly, it may be due to learners' lack of awareness as well as lack of knowledge: when they learnt the simple past tense, the learners tried to overgeneralize other forms (stage 7) instead of the simple past tense e.g. have or has + simple past, thinking that it might be the correct simple past form.

The above interpretations led the researcher to ensure the influence of L1 in acquiring L2, and the contrastive interference from the target language in the acquisition of L2 grammar in the context the ALEs as foreign language learners in the classroom context.

In my opinion it might be reasonable to propose two additional strategies in the acquisition of the simple past in the context of ALEs. The two additional strategies proposed are: the L1 Transfer Strategy and the Overgeneralization of Alternative L2 Category Strategy. These strategies will be presented in the following sections 4.1-2.

\section{A. L1 Transfer Strategy}

One of the proposed strategies in this study is the L1 Transfer Strategy. One explanation of this proposed strategy is the particular forms produced by ALEs due to the differences between L1 and L2. This strategy seems to suggest two types: the first type is using the verb to be + stem, agent, simple past, past participle or gerund. The second type is using to + stem, or simple past. The first type is illustrated below.

\section{Type one}

The tables below show the occurrence of the sub-types of the L1 Transfer Strategy in both groups. Table 1 shows applying the L1 Transfer Strategy to the three chronological writings (Type One).

TABLE 1:

USING VERB TO BE + STEM, SIMPLE PAST, PAST PARTICIPLE, OR GERUND

\begin{tabular}{llll}
\multicolumn{4}{c}{ USING VERB TO BE + STEM, SIMPLE PAST, PAST PARTICIPLE, OR GERUND } \\
\hline Stage & The First Group & The Second Group & Total \\
\hline$B$ & 26 & 15 & 41 \\
$M$ & 1 & 6 & 7 \\
$F$ & 2 & 4 & 6 \\
\hline Total & 29 & 25 & 54 \\
\hline
\end{tabular}

\section{Type two}

Table 2 shows applying the L1 Transfer Strategy to the three chronological writings (Type Two), where ALEs use to + stem or simple past

TABLE 2:

\begin{tabular}{llll}
\multicolumn{4}{c}{ USING TO + STEM, SIMPLE PAST } \\
\hline Stage & The First Group & The Second Group & Total \\
\hline$B$ & 3 & 7 & 10 \\
$M$ & 1 & 2 & 3 \\
$F$ & 1 & 1 & 2 \\
\hline Total & 5 & 10 & 15 \\
\hline
\end{tabular}

\section{B. Overgeneralization of Alternative L2 Category Strategy}

The second proposed strategy may be the Overgeneralization of Alternative L2 Category Strategy, which represents the contrastive interference from the target language. In this strategy, the learners use alternative forms of the simple past which are: the present perfect forms 7; the present continuous 4; the past continuous 9; the gerund 19; the past participle 2; and finally nouns 3 . They think that the alternative forms can give the same meaning as the simple past in the English grammar. It is worth mentioning that learners in both groups used more alternative forms in writing B. Then it decreased dramatically in writing $\mathrm{M}$ and F. The prevalence of the Overgeneralization of Alternative L2 Category Strategy in the first writing - stage B- seems to suggest that learners' lack of knowledge or the fluctuation in producing the target-like simple past tense forms operate at the beginning of the course. It is worth mentioning that, after the ALEs spent more time learning the simple past tense forms, the Overgeneralization of Alternative L2 Category Strategy decreased as is shown clearly in Table 3 . Most of these forms rarely appear at stages $\mathrm{M}$ and F. 
TABLE 3:

\begin{tabular}{llll} 
Stage & The First Group & The Second Group & Total \\
\hline$B$ & 11 & 12 & 23 \\
$M$ & 6 & 6 & 12 \\
$F$ & 4 & 5 & 9 \\
\hline Total & 21 & 23 & 44 \\
\hline
\end{tabular}

It is worth mentioning that the two strategies added by the researcher to the acquisition of the simple past in the context of the ALEs are the same different interlanguage stages found in the context of the ALEs in the acquisition of the simple past tense forms from the interlanguage stages found in other studies (Mourssi, 2012a and 2012c).

\section{CONCLUSION}

To sum up, most of the past tense forms produced by the subjects in the first and second groups appear to indicate ccrosslinguistic influence of L1 (Arabic) in acquiring linguistic items of L2 (English) in the context of Arab Learners of English as undergraduate learners. It also indicates that the two additional strategies, namely, the L1 Transfer Strategy and the L2 Overgeneralization of Alternative L2 Category Strategy, represent the specific characteristics of the ALEs in the acquisition of the simple past tense in English.

\section{REFERENCES}

[1] Adjemian, C. (1976). On the nature of Interlanguage systems. Language Learning. Volume 26, 297-320.

[2] Cook, V. J. (2001). Second Language Acquisition. Oxford: Oxford University Press.

[3] Cross, D. (1991). A Practical Handbook of Language Teaching. London: Cassell.

[4] Crystal, D. (2008). A Dictionary of Linguistics and Phonetics, 5th ed. Oxford: Blackwell Publishing.

[5] Dickens, P. and E. Woods, (1988). Some criteria for the development of communicative grammar tasks. TESOL Quarterly, Volume 22 (4), 194195.

[6] Dulay, H. and M. Burt. (1973). Should we teach children syntax? Language Learning. Volume 23, 245-58.

[7] Dulay, H. and M. Burt. (1974). Natural sequences in child second-language acquisition. Language Learning. Volume 25(1), 37-53.

[8] Dulay, H., M. Burt, and S. Krashen, (1982). Language Two. Oxford: Oxford University Press.

[9] Ellis, R. (1984). Classroom Second Language Development. A study of classroom Interaction and Language Acquisition. Oxford: Pergamon.

[10] Ellis, R. (1987). Interlanguage variability in narrative discourse: style shifting in the use of the past tense. Studies in Second Language Acquisition. Volume 9, 1-20.

[11] Ellis, R. (1997). Second Language Acquisition. Oxford: Oxford University Press.

[12] Fasold, R. and D. Preston. (2007). The psycholinguistic unity of inherent variability: Old Occam whips out his razor. in: R. Bayley and C. Luca, (eds), Sociolinguistic Variation: Theory, Methods and Applications. Cambridge: Cambridge University Press, 45-69.

[13] Fuller, J. and J. Gundel, (1987). Topic prominence in Interlanguage. Language Learning, Volume 37, 1-18.

[14] Gao, H. (2001). The physical foundation of the patterning of physical action verbs. Lund, Sweden: Lund University Press.

[15] Gass, S. (1997). Input, Interaction, and the Second Language Learner. Mahwah. NJ: Lawrence Erlbaum Associates.

[16] Gass, M. and L. Selinker. (2008). Second language Acquisition. An Introductory Course. Third edition. Mahwah, N.J.: Lawrence Erlbaum Associates.

[17] Harmer, J. (1991). The Practice of English Language Teaching. London: Longman.

[18] Hymes, D. (1972). Models of the Interaction of language and social life. In: J. Gumperz, and D. Hymes, (eds.). Directions in sociolinguistics: ethnography of communication. New York, N Y: Holt, Rinehert \& Winston, 35-71.

[19] Ismail, S. (2010). ESP Students' Views of ESL Grammar Learning. Journal of Language Studies Volume 10 (3), 143-156.

[20] Jarvis, S. and A. Pavlenko. (2008). Crosslinguistic Influence in Language and Cognition. New York: Routledge

[21] Klein, W. (1986). Second Language Acquisition. Cambridge: Cambridge University Press.

[22] Kleinman, H. (1977). Avoidance behaviour in adult second-language acquisition. Language Learning. Volume 27, 93-105.

[23] Lado, R. (1957). Linguistics Across Cultures. Applied Linguistics for Language Teachers. Ann Arbor: University of Michigan Press.

[24] Lakshmanan, U. and L. Selinker. (2001). Analyzing Interlanguage: How do we know what learners know? Second Language Research. Volume 17 (4), 393-420.

[25] Larsen-Freeman, D. and M. H. Long. (1991). An Introduction to Second Language acquisition Research. Harlow: Longman.

[26] Leech, G. and J. Svartvik. (1982). A communicative grammar of English. London: Longman.

[27] Lock, G. (1996). Functional English Grammar: An introduction for second language teachers. Cambridge Language Education. Cambridge New York: Cambridge University Press.

[28] Mansouri, F. (2005). Agreement morphology in Arabic as a second language: Typological features and their processing implications. In: Pienemann, M. (2005) Cross-linguistic Aspects of Processability Theory. Amsterdam: Benjamins, 117-153.

[29] Mourssi, A. (2013a). The Role of Revising and Redrafting in Improving Second Language Learners' Writing: The Acquisition of the Simple Past. Unpublished doctoral dissertation, UWE, Bristol, UK.

[30] Mourssi, A. (2013b). The Efficacy of Ex-implicit in between Implicit and Explicit Grammar Teaching Approach on Second/Foreign Language Learners' Writing. The International Journal of Language Learning and Applied Linguistics World, Volume 2 (2), 43-53. 
[31] Mourssi, A. (2012a). Analyzing Interlanguage Stages ALEs Pass Through in the Acquisition of the Simple Past Tense, English Language Teaching; Volume. 5 (1), 148-163.

[32] Mourssi, A. (2012b). The impact of Reflection and Metalinguistic Feedback in SLA: A Qualitative Research in the Context of Post Graduates. The International Journal of Language Learning and Applied Linguistics World, Volume 1 (1), 122-139.

[33] Mourssi, A. (2012c). The Acquisition of the Simple Past Tense in the Context of Arab Learners of English, Arab World English Journal, Volume. 3 (3), 204-222

[34] Mourssi, A. (2012d). The Innovated Writing Process (IWP) Approach: a Practical Bridge between Recent SLA and Applied Linguistics Theories, English Linguistics Research, Volume 1 (2), 102-118.

[35] Mourssi, A. (in press). The relevance of the U-shaped Learning model to the acquisition of the simple past tense in the Arab Learners' of English. Linguistics, Culture \&Education.

[36] Odlin, T. (1989). Language Transfer. Cambridge: Cambridge University Press.

[37] Pienemann, M. (1984). Psychological constraints on teachability of languages. Studies in Second Language Acquisition. Volume 6, 186-214.

[38] Pienemann, M. (1998). Language processing and Second Language Development: Processability Theory. Amsterdam: Benjamins.

[39] Richard-Amato, P. (2003). Making it happen: from interactive to participatory language teaching. Theory and Practice. White Plains. NY. Longman.

[40] Richards, J. (ed.) (1974). Error Analysis: Perspectives on Language Acquisition. London: Longman.

[41] Scarcella, R. and R. Oxford. (1992). The tapestry of Language Learning: The individual in the communicative classroom. Boston: Heinle \& Heinle.

[42] Selinker, L. (1969). Language transfer. General Linguistics. Volume 9, 67-92.

[43] Spada, N. and P. M. Lightbown. (1999). Instruction, first language influence and developmental readiness in second language acquisition. The Modern Language Journal. Volume 83(1), 1-22.

[44] Taatgen, N. A. and J. R. Anderson. (2002). Why do children learn to say "Broke"? A model of learning the past tense without feedback. Cognition. Volume 86, 123-155.

[45] Taatgen, N. and M. Dijkstra. (2005). Constraints on Generalization: why are Past-Tense Irregularization Errors so rare? Proceeding of the $25^{\text {th }}$ annual conference of the cognitive science society. Mahwah, NJ: Erlbaum.

[46] Tarone, E., M. Bigelow, and K. Hansen. (2009). Literacy and Second Language Oracy. Oxford: Oxford University Press.

[47] Williams, J. and J. Evans. (1998). "What kind of focus and on which forms?" in: C. Doughty and J. Williams. (eds.) Focus on Form in Classroom Second Language Acquisition. Cambridge: Cambridge University Press, 139-155.

Anwar Mourssi was born on May 17, 1967 in Egypt. He received his M.A in TESL/TEFL from Birmingham University/UK in 2006, and his $\mathrm{PhD}$ in Applied Linguistics from University of the West of England, Bristol/UK in 2012. His major field of study is Second Language Acquisition.

He has worked as a teacher of English language for about 16 years and as a lecturer of Applied Linguistics core subject for about six years, and currently he is a lecturer of Technical Writing and Technical Communication at Higher College of Technology, Muscat, Oman. He has published and edited a number of research articles.

Dr. Mourssi is now on the editorial board of some language journals in Norway, Canada and the UK. He is a member in the Editorial Board in the International journal of Language Learning and Applied Linguistics World, Norway, also a member in LINGUISTNET research network, University of Bristol Graduate School of Education, the United Kingdom, and a member in the Editorial Board in Study in English Language Teaching Journal, The United Kingdom and finally, he is a member in Moroccan Association of Teachers of English MATE, Morocco. 